\title{
Lack of association of cytomegalovirus with human brain tumors
}

\author{
Sean K Lau ${ }^{1}$, Yuan-Yuan Chen ${ }^{1}$, Wen-Gang Chen ${ }^{1}$, Don J Diamond ${ }^{2}$, Adam N Mamelak ${ }^{3}$, \\ John A Zaia ${ }^{2}$ and Lawrence M Weiss ${ }^{1}$ \\ ${ }^{1}$ Department of Pathology, City of Hope National Medical Center, Duarte, CA, USA; ${ }^{2}$ Division of Virology, \\ Beckman Research Institute, City of Hope National Medical Center, Duarte, CA, USA and ${ }^{3}$ Division of \\ Surgery, City of Hope National Medical Center, Duarte, CA, USA
}

\begin{abstract}
Cytomegalovirus (CMV) is thought to possess oncogenic properties and has been linked with a number of human malignancies. CMV infection was recently described in association with malignant gliomas. The intent of the present study was to further investigate the reported association between CMV and malignant gliomas. Tissue from 22 brain tumors of various histologic types and grades, four normal brains, six breast carcinomas, six colon carcinomas, six lung carcinomas, and six sarcomas were evaluated for the presence of CMV by polymerase chain reaction (PCR), in situ hybridization, and immunohistochemical methods. None of the brain tumors or normal brain tissue tested demonstrated evidence of CMV pp65 or early nuclear proteins by immunohistochemistry. In addition, no CMV RNA or DNA was detected in these cases by in situ hybridization and PCR. None of the carcinomas or sarcomas evaluated were positive for CMV by immunohistochemistry, in situ hybridization, or PCR. The findings of the present study suggest that CMV is not significantly associated with brain tumors in humans.
\end{abstract}

Modern Pathology (2005) 18, 838-843, advance online publication, 3 December 2004; doi:10.1038/modpathol.3800352

Keywords: cytomegalovirus; brain tumor; glioma

The etiology of primary malignant brain tumors remains largely unknown. While there is general agreement that inherited and genetic factors influence brain tumor development, the potential role of other environmental contributors remains unclear. ${ }^{1,2}$ Among the many suggested environmental risk factors associated with brain tumors, only exposure to ionizing radiation has been recognized as an etiologic agent in the development of brain neoplasms. ${ }^{3,4}$ In contrast, the role of viral infections in the evolution of brain tumors is still poorly understood.

While DNA from several types of polyoma viruses has been detected in a variable percentage of human brain tumors, ${ }^{5-9}$ there has been no conclusive evidence to indicate that such viral agents directly promote tumorigenesis. Simian virus 40 , a contaminant of polio vaccines utilized between 1955 and $1963,{ }^{8-10}$ in particular has been implicated as a causative agent in the development of neurologic

Correspondence: Dr SK Lau, MD, Department of Pathology, City of Hope National Medical Center, 1500 East Duarte Road, Duarte, CA 91010, USA.

E-mail: SLau@coh.org

Received 27 August 2004; revised 18 October 2004; accepted 20 October 2004; published online 3 December 2004 malignancies, as viral sequences have been detected in brain tumors at an overall frequency of approximately $35 \% .{ }^{9-12}$ However, epidemiological data have not supported a clear relationship between virus-contaminated vaccinations and an increased risk for brain tumors. ${ }^{8,10,13}$

Human cytomegalovirus (CMV) possesses many oncogenic properties and has been linked to several different human malignancies. ${ }^{14-17}$ CMV has not been well investigated in the context of malignant gliomas, but a recent report has documented the presence of CMV in a number of these tumors. ${ }^{18}$ In this particular study, Cobbs et $a l^{18}$ demonstrated immunohistochemical evidence of CMV IE1-72 protein in 27 of 27 gliomas of different histologic grades, with CMV pp65 protein also detected in a subset of these cases. CMV nucleic acids were also observed in a number of these tumors by in situ hybridization and polymerase chain reaction (PCR) methods. In contrast, CMV was not detected in tissue derived from normal brains and brains involved by non-neoplastic neurologic processes, suggesting a potential role for the virus in the pathogenesis of gliomas.

In order to further investigate the relationship between CMV and gliomas, we analyzed a series of brain tumors of various histologic types and grades 
for evidence of CMV infection. The presence of CMV was evaluated by determining the expression of CMV proteins by immunohistochemistry and the presence of viral genomes by in situ hybridization and PCR.

\section{Materials and methods}

\section{Patient Samples}

City of Hope National Medical Center Institutional Review Board approval was obtained for this study. The material used in this study was obtained from the files of the Department of Pathology at the City of Hope National Medical Center and consisted of 22 brain tumors, four normal brains, six breast carcinomas, six colon carcinomas, six lung carcinomas, and six sarcomas. The brain tumors were classified and graded according to World Health Organization criteria $^{19}$ and consisted of eight cases of glioblastoma (WHO grade IV), six anaplastic astrocytomas (WHO grade III), three diffuse astrocytomas (WHO grade II), two oligodendrogliomas (WHO grade II), and three ependymomas (WHO grade II). Formalinfixed paraffin-embedded tissue from each case was utilized for PCR, in situ hybridization, and immunohistochemical studies as described below.

\section{Polymerase Chain Reaction}

Total DNA was extracted from formalin-fixed, paraffin-embedded tissue sections, using $0.2 \mathrm{mg} /$ ml. of proteinase $\mathrm{K}$ digestion at $55^{\circ} \mathrm{C}$ overnight, followed by denaturation by boiling. The PCR studies were performed with $2 \mu \mathrm{l}$ of extracted DNA in a $30 \mu \mathrm{l}$ mixture containing $50 \mathrm{mmol} / \mathrm{l}$ KCL, $10 \mathrm{mmol} / \mathrm{l}$ Tris buffer (pH 8.3), $50 \mu \mathrm{m}$ of each deoxynucleotide triphosphate, $2.5 \mathrm{mmol} / \mathrm{l} \mathrm{MgCl}_{2}$, $1 \mathrm{U}$ of HotStarTaq DNA Polymerase (QIAGEN, Valencia, CA, USA), and $20 \mathrm{pmol}$ of each primer. External and internal oligonucleotide primers specific for CMV glycoprotein B gene were utilized. ${ }^{20}$ The external primers used were 5'-TCCAACACC CACAGTACCCGT-3' ${ }^{\prime}$ and $5^{\prime}$-CGGAAACGATGGTG TAGTTCG- $3^{\prime}$ and the internal primers used were $5^{\prime}$ TGACGGTCAAGGATCAGTGGC- $3^{\prime}$ and $5^{\prime}$-GTAAA CCACATCACCCGTGGA-3' . The expected amplification product size was $146 \mathrm{bp}$. After initial denaturation for $15 \mathrm{~min}$ at $95^{\circ} \mathrm{C}, 45$ amplification cycles were performed as follows: denaturing at $94^{\circ} \mathrm{C}$ for $30 \mathrm{~s}$, annealing for $30 \mathrm{~s}$ at $56^{\circ} \mathrm{C}$, and extension at $72^{\circ} \mathrm{C}$ for $40 \mathrm{~s}$. A final extension at $72^{\circ} \mathrm{C}$ for $7 \mathrm{~min}$ completed the PCR amplification. The PCR setup and post-PCR work were performed in separate laboratories to minimize the possibility of contamination. Primers flanking the $\beta$-globin gene were used as a positive control for DNA preservation (expected PCR product size was $268 \mathrm{bp}$ ) and DNA derived from known CMV-positive colonic tissue from an immunocompromised organ transplant recipient was used as a positive control. The amplified products obtained were separated by electrophoresis on gels and visualized with ethidium bromide staining under ultraviolet light. PCR products were subsequently subjected to Southern blot analysis and hybridized with an appropriate probe (5'-AAGGATACTTGGAGCGCGCAGTA-3').

\section{In Situ Hybridization}

In situ hybridization was performed using a digoxigenin-labeled 21 base oligonucleotide probe (5'GTGGTGGCGCTGGGGGTGGCG-3') complementary to highly expressed CMV early gene messenger RNA (mRNA). A second probe specific for CMV DNA was also utilized, constructed from CMV pp65 ${ }^{21}$ and pp150 ${ }^{22}$ plasmids. The plasmids were digested using SaII/BamHI and BamHI/EcoRI, respectively. The inserts were run on an agarose gel and purified using a QIAEX II Extraction Kit (Qiagen, Valencia, CA, USA). The HCMV DNA probe was labeled with biotin using the Megaprime DNA Labelling System (Amersham Biosciences, Piscataway, NJ, USA).

Sections cut from formalin-fixed paraffin-embedded tissue were deparaffinized, digested with pronase, and then hybridized overnight with the digoxigenin-labeled oligonucleotide probe. Sections were then washed with $2 \times$ SSC, incubated with $2 \%$ normal sheep serum in $0.3 \%$ Triton in Tris-saline buffer ( $\mathrm{pH} 7.5$ ) for $30 \mathrm{~min}$ at room temperature, and subsequently incubated with Anti-Digoxigenin-AP, Fab fragments (1:500 dilution) (Roche Applied Science, Germany) for $2 \mathrm{~h}$ at room temperature. Sections were subsequently washed for $3 \mathrm{~min}$ in Tris-saline buffer, incubated in McGadey's substrate at $37^{\circ} \mathrm{C}$ for $1 \mathrm{~h}$, briefly washed in distilled water, air dried, and coverslipped. No counterstain was used. A poly $d(T)$ was used as a control for total RNA preservation as described elsewhere. ${ }^{23}$ In situ hybridization utilizing the CMV DNA probe was performed in a similar fashion. Following application of the probe to deparaffinized and digested tissue sections, the sections were denatured at $92^{\circ} \mathrm{C}$ for $10 \mathrm{~min}$ and then hybridized overnight at $37^{\circ} \mathrm{C}$. Detection was performed using avidin alkaline phosphatase conjugate and McGadey's substrate. CMV-positive colonic tissue from an immunocompromised organ transplant recipient was used as a positive control.

\section{Immunohistochemistry}

Immunohistochemical staining was performed on formalin-fixed, paraffin-embedded sections using the following monoclonal antibodies: anti-CMV (clones CCH2 and DDG9, dilution 1:200, DAKO, Carpinteria, CA, USA), which is a cocktail of two antibodies that react with a $76 \mathrm{kDa}$ HCMV early protein and the delayed early DNA binding protein p52, and anti-pp65 (clones 2 and 6, dilution 1:50, 
Novocastra, Newcastle upon Tyne, UK), which is specific for CMV pp65 protein. Slides were pretreated by proteolytic digestion with proteinase $\mathrm{K}$ (DAKO) for $5 \mathrm{~min}$ (anti-CMV) or by steam heating slides in citrate buffer ( $\mathrm{pH}$ 6.0) in a steamer (Black and Decker, Shelton, CT, USA) for $20 \mathrm{~min}$ (antipp65). Staining was performed using an automated immunostainer (DAKO), followed by antibody detection using the DAKO EnVision + System and $3,3^{\prime}$-diaminobenzidine as a chromogen. The slides were counterstained with hematoxylin and coverslipped. Sections of known CMV-positive colonic tissue from an immunocompromised organ transplant recipient were used as a positive control.

\section{Results}

The results of the CMV studies are summarized in Table 1. All astrocytic, oligodendroglial, and ependymal tumors of the brain examined demonstrated no evidence of CMV proteins by immunohistochemistry utilizing anti-CMV and anti-pp65 antibodies. Samples of normal brain were likewise immunohistochemically negative for CMV proteins. Using an oligonucleotide probe specific for CMV early gene mRNA, positive signals indicative of CMV mRNA were identified in positive control tissue, but not in any of the brain tumors and normal brain tissues analyzed by in situ hybridization. All cases studied exhibited strong positivity for poly $\mathrm{d}(\mathrm{T})$, indicating adequate RNA preservation. In addition, in situ hybridization was also performed using a probe for CMV DNA, which similarly detected no CMV nucleic acids in the neoplastic and normal brain tissues studied. Each case was further analyzed for the presence of CMV DNA by PCR. The primers utilized amplified a band of the appropriate size from the positive control tissue; however, none of the brain neoplasms or non-neoplastic brain tissues examined yielded a PCR product indicative of CMV DNA (Figure 1a). Strong $\beta$-globin amplified bands were identified by PCR from all cases, indicating adequate DNA present (Figure 1b). All carcinomas of the breast, lung, and colon, as well as each of the sarcomas studied were negative for CMV by immunohistochemistry, in situ hybridization, and PCR methods.

\section{Discussion}

CMV is a widely distributed herpesvirus associated with a broad spectrum of clinical diseases. The virus is capable of establishing persistent and latent infections that are usually asymptomatic, but can cause significant disease in neonates and immunosuppressed individuals. CMV has also been viewed as a potential oncogenic virus. In vitro studies have demonstrated the ability of whole virus and viral DNA fragments to transform mammalian cells morphologically. ${ }^{14-17}$ In addition, CMV infection has been shown to stimulate nucleic acid and protein synthesis, activate transcription of protooncogenes, and modulate expression of proteins involved in cellular regulatory and apoptotic pathways. ${ }^{14-17,24-27}$ CMV has been associated with several specific human malignancies including carcinomas of the cervix, ${ }^{28-32}$ prostate,,$^{33-36}$ and colon. ${ }^{37-39}$ However, a number of conflicting reports have either failed to show evidence of an association with CMV or have questioned the significance of the presence of CMV in these particular tumors. ${ }^{40-45}$

There is relatively little information in the literature pertaining to CMV and brain neoplasms. Astrocytoma and glioblastoma cell lines have been shown to be at least somewhat permissive to CMV infection in vitro, ${ }^{46}$ and a recent seroepidemiologic study has demonstrated that patients with glioblastoma multiforme were somewhat more likely to have antibodies to CMV than controls. ${ }^{47}$ More direct evidence suggesting an association of CMV with gliomas has been provided in a recent study by Cobbs et $a{ }^{18}{ }^{18}$ In this particular study, the CMVencoded IE1-72 protein was detected in the tumor cells of 27 of 27 gliomas of various grades by immunohistochemistry. A subset of these tumors also exhibited immunohistochemical positivity for

Table 1 Results of CMV studies in brain tumors, normal brain, carcinomas, and sarcomas

\begin{tabular}{|c|c|c|c|c|c|}
\hline \multirow[t]{2}{*}{ Tumor type } & \multicolumn{2}{|c|}{$I H C$} & \multicolumn{2}{|c|}{$I S H$} & \multirow{2}{*}{$\frac{P C R}{C M V D N A}$} \\
\hline & Anti-pp65 & Anti-CMV & CMV RNA & $C M V D N A$ & \\
\hline Glioblastoma & $0 / 8$ & $0 / 8$ & $0 / 8$ & $0 / 8$ & $0 / 8$ \\
\hline Anaplastic astrocytoma & $0 / 6$ & $0 / 6$ & $0 / 6$ & $0 / 6$ & $0 / 6$ \\
\hline Diffuse astrocytoma & $0 / 3$ & $0 / 3$ & $0 / 3$ & $0 / 3$ & $0 / 3$ \\
\hline Oligodendroglioma & $0 / 2$ & $0 / 2$ & $0 / 2$ & $0 / 2$ & $0 / 2$ \\
\hline Ependymoma & $0 / 3$ & $0 / 3$ & $0 / 3$ & $0 / 3$ & $0 / 3$ \\
\hline Normal brain & $0 / 4$ & $0 / 4$ & $0 / 4$ & $0 / 4$ & $0 / 4$ \\
\hline Breast carcinoma & $0 / 6$ & $0 / 6$ & $0 / 6$ & $0 / 6$ & $0 / 6$ \\
\hline Colon carcinoma & $0 / 6$ & $0 / 6$ & $0 / 6$ & $0 / 6$ & $0 / 6$ \\
\hline Lung carcinoma & $0 / 6$ & $0 / 6$ & $0 / 6$ & $0 / 6$ & $0 / 6$ \\
\hline Sarcoma & $0 / 6$ & $0 / 6$ & $0 / 6$ & $0 / 6$ & $0 / 6$ \\
\hline
\end{tabular}


174 bp

$102 \mathrm{bp}$
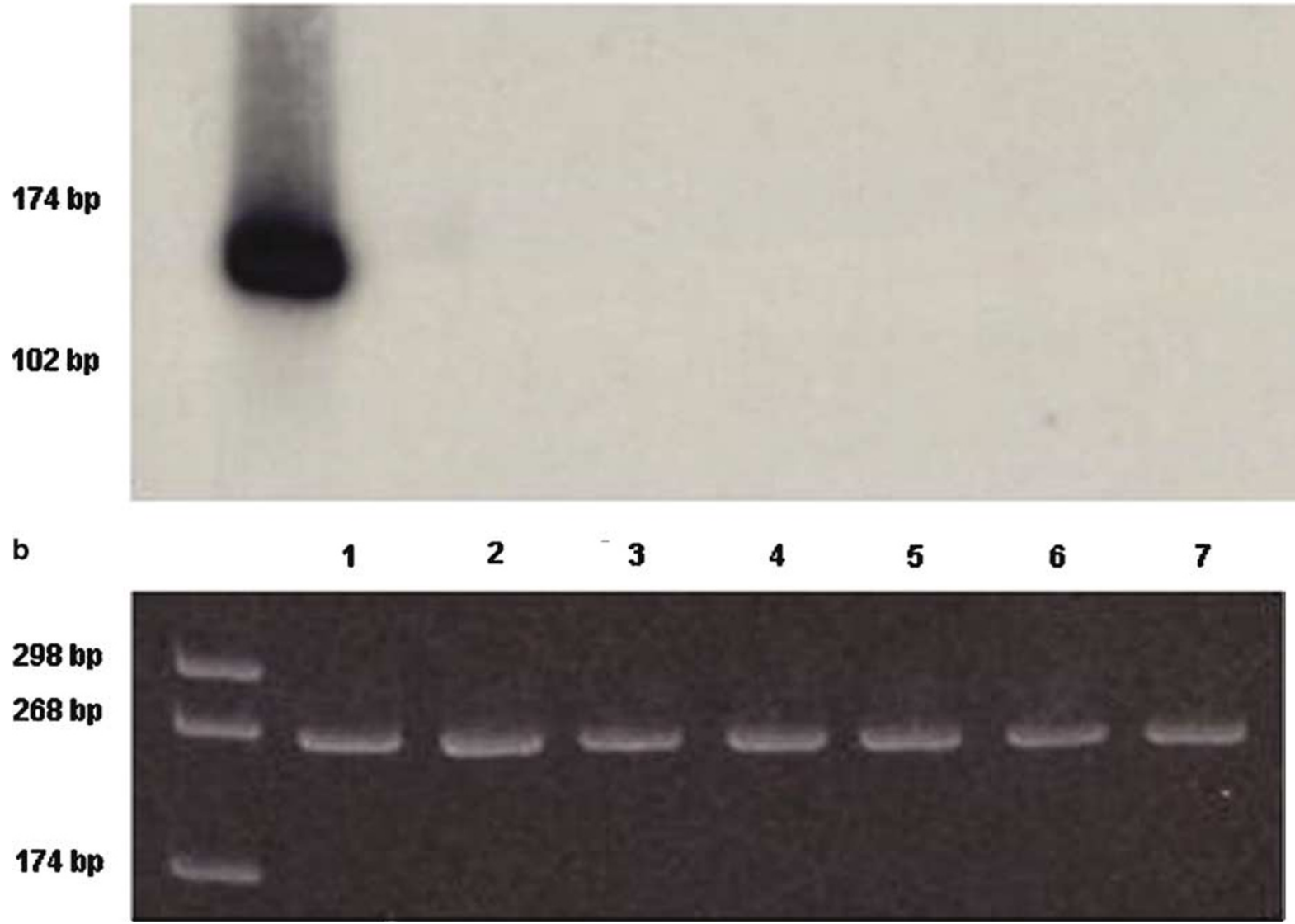

Figure 1 (a) Southern blot hybridization of PCR products after amplification of CMV DNA. A positive control ( +) exhibiting a 146 bp product is seen at the far left. No PCR products indicative of CMV infection are detected in representative cases of glioblastoma (lanes 13), anaplastic astrocytoma (lanes 4, 5), diffuse astrocytoma (lane 6), or normal brain (lane 7). (b) Electrophoretic analysis of PCR products obtained from above cases with primers for the $\beta$-globin gene. PCR products of the appropriate size (268 bp) are detected in all cases, indicating suitable DNA present.

pp65 and CMV early proteins. The presence of CMV in these tumors was also demonstrated by in situ hybridization as well as by PCR. However, no CMV was identified in a control group of normal brain tissues, suggesting that the presence of CMV may play a possible role in glioma development.

In contrast to the findings of this previous report, ${ }^{18}$ in the present study, no immunohistochemical evidence of CMV protein expression was identified in any of the gliomas examined using monoclonal antibodies specific for CMV pp65 and early nuclear antigens. The absence of CMV protein expression in the brain tumors was also consistent with the observed in situ hybridization and PCR results, which likewise failed to demonstrate the presence of CMV mRNA and DNA. The reasons for this difference in observed positivity for CMV are unclear, as we used an in situ hybridization probe and PCR primers for specific CMV nucleic acids similar to those employed by Cobbs et al. ${ }^{18}$ Minor differences in techniques and experimental conditions may be responsible for this discrepancy in results. Although immunohistochemical evaluation of CMV IE1-72 protein expression was not performed in the present study, we did utilize a monoclonal antibody which reacts with CMV pp65 protein, in addition to a cocktail of two monoclonal antibodies specific for CMV early nuclear antigens that has been previously demonstrated to be a highly sensitive and specific method of detecting CMV infection. ${ }^{48-50}$

The findings of the current study are limited somewhat by the relatively small number of cases that were evaluated. In addition, it should be noted that this study focused primarily on gliomas, and did not specifically address neuronal, embryonal, or meningeal neoplasms. As such, an association between CMV and these particular types of central nervous system malignancies cannot be excluded.

Although a number of viruses have been shown to induce brain neoplasms in experimental animal systems, and viral genomic sequences have been detected in human brain tumors, a causal link between viral infections and nervous system malignancies has not been conclusively established. ${ }^{51}$ The findings of the present study demonstrate no strong 
evidence for an association between CMV and various histologic types of brain neoplasms. The lack of localization of CMV by morphological and molecular analyses in these cases argues against a role for the virus in the etiology of brain tumors in humans. Further studies, which include larger numbers of cases and a broader spectrum of central nervous system neoplasms, are required to confirm the validity of these results.

\section{References}

1 Wrensch M, Bondy ML, Wiencke J, et al. Environmental risk factors for primary malignant brain tumors: a review. J Neurooncol 1993;17:47-64.

2 Inskip PD, Linet MS, Heineman EF. Etiology of brain tumors in adults. Epidemiol Rev 1995;17:382-414.

3 Liwnicz BH, Berger TS, Liwnicz RG, et al. Radiationassociated gliomas: a report of four cases and analysis of postradiation tumors of the central nervous system. Neurosurgery 1985;17:436-445.

4 Cavin LW, Dalrymple GV, McGuire EL, et al. CNS tumour induction by radiotherapy: a report of four new cases and estimate of dose required. Int J Radiat Oncol Biol Phys 1990;18:399-406.

5 Dorries K, Loeber G, Meixensberger J. Association of polyomaviruses JC, SV40, and BK with human brain tumors. Virology 1987;160:268-270.

6 Corallini A, Pagnani M, Viadana P, et al. Association of BK virus with human brain tumors and tumors of pancreatic islets. Int J Cancer 1987;39:60-67.

7 Negrini M, Rimessi P, Mantovani C, et al. Characterization of BK virus variants rescued from human tumours and tumour cell lines. J Gen Virol 1990;71:2731-2736.

8 Geissler E. SV40 and human brain tumors. Prog Med Virol 1990;37:211-222.

9 Butel JS, Lednicky JA. Cell and molecular biology of simian virus 40: implications for human infections and disease. J Natl Cancer Inst 1999;91:119-134.

10 Carbone M, Rizzo P, Pass HI. Simian virus 40, poliovaccines and human tumors: a review of recent developments. Oncogene 1997;15:1877-1888.

11 Martini F, Iaccheri L, Lazzarin L, et al. SV40 early region and large $\mathrm{T}$ antigen in human brain tumors, peripheral blood cells, and sperm fluids from health individuals. Cancer Res 1996;56:4820-4825.

12 Huang H, Reis R, Yonekawa Y, et al. Identification in human brain tumors of DNA sequences specific for SV40 large T antigen. Brain Pathol 1999;9:33-42.

13 Ohgaki H, Huang H, Haltia M, et al. More about cell and molecular biology of simian virus 40: implications for human infections and disease. J Natl Cancer Inst 2000;92:495-497.

14 Rapp F, Robbins D. Cytomegalovirus and human cancer. Birth Defects Orig Artic Ser 1984;20:175-192.

15 Huang ES, Mar EC, Boldogh I, et al. The oncogenicity of human cytomegalovirus. Birth Defects Orig Artic Ser 1984;20:193-211.

16 Spector DH, Spector SA. The oncogenic potential of human cytomegalovirus. Prog Med Virol 1984;29: 45-89.

17 Doniger J, Muralidhar S, Rosenthal LJ. Human cytomegalovirus and human herpesvirus 6 genes that transform and transactivate. Clin Microbiol Rev 1999;12:367-382.
18 Cobbs CS, Harkins L, Samanta M, et al. Human cytomegalovirus infection and expression in human malignant glioma. Cancer Res 2002;62:3347-3350.

19 Kleihues P, Cavenee WK, (eds). World Health Organization Classification of Tumours: Pathology and Genetics of Tumours of the Nervous System. IARC Press: Lyon, 2000.

20 Kuhn JE, Wendland T, Eggers HJ, et al. Quantitation of human cytomegalovirus genomes in the brain of AIDS patients. J Med Virol 1995;47:70-82.

21 Pande H, Baak SW, Riggs $\mathrm{AD}$, et al. Cloning and physical mapping of a gene fragment coding for a 64kilodalton major late antigen of human cytomegalovirus. Proc Natl Acad Sci USA 1984;81:4965-4969.

22 Pande H, Campo K, Churchill MA, et al. Genomic locus for a $140 \mathrm{kDa}$ structural protein (pp150) of human cytomegalovirus in strains Towne and AD169. Virus Res 1989;12:11-18.

23 Weiss LM, Chen YY. Effects of different fixatives on detection of nucleic acids from paraffin-embedded tissues by in situ hybridization using oligonucleotide probes. J Histochem Cytochem 1991;39: 1237-1242.

24 Boldogh I, AbuBakar S, Deng, CZ, et al. Transcriptional activation of cellular oncogenes fos, jun, and myc by human cytomegalovirus. J Virol 1991;65:1568-1571.

25 Jault FM, Jault JM, Ruchti F, et al. Cytomegalovirus infection induces high levels of cyclins, phosphorylated $\mathrm{Rb}$, and $\mathrm{p} 53$, leading to cell cycle arrest. J Virol 1995;69:6697-6704.

26 Zhu H, Shen Y, Shenk T. Human cytomegalovirus IE1 and IE2 proteins block apoptosis. J Virol 1995;69: 7960-7970.

27 Cinatl Jr J, Cinatl J, Vogel JU, et al. Modulatory effects of human cytomegalovirus infection on malignant properties of cancer cells. Intervirology 1996;39: 259-269.

28 Vestergaard BF, Hornsleth A, Pedersen SN. Occurrence of herpes- and adenovirus antibodies in patients with carcinoma of the cervix uteri. Measurement of antibodies to herpesvirus hominis (types 1 and 2), cytomegalovirus, EB-virus, and adenovirus. Cancer 1972;30:68-74.

29 Melnick JL, Lewis R, Wimberly I, et al. Association of cytomegalovirus (CMV) infections with cervical cancer: isolation of CMV from cell cultures derived from cervical biopsy. Intervirology 1978;10:115-119.

30 Fletcher K, Cordiner JW, Macnab JC. Detection of sequences that hybridize to human cytomegalovirus DNA in cervical neoplastic tissue. Dis Markers 1986;4:219-229.

31 Shen CY, Ho MS, Chang SF, et al. High rate of concurrent genital infections with human cytomegalovirus and human papillomaviruses in cervical cancer patients. J Infect Dis 1993;168:449-452.

32 Han CP, Tsao YP, Sun CA, et al. Human papillomavirus, cytomegalovirus and herpes simplex virus infections for cervical cancer in Taiwan. Cancer Lett 1997;120:217-221.

33 Geder L, Sanford EJ, Rohner TJ, et al. Cytomegalovirus and cancer of the prostate: in vitro transformation of human cells. Cancer Treat Rep 1977;61:139-146.

34 Sanford EJ, Geder L, Laychock A, et al. Evidence for the association of cytomegalovirus with carcinoma of the prostate. J Urol 1977;118:789-792.

35 Boldogh I, Baskar JF, Mar EC, et al. Human cytomegalovirus and herpes simplex type 2 virus in normal and 
adenocarcinomatous prostate glands. J Natl Cancer Inst 1983;70:819-826.

36 Samanta M, Harkins L, Klemm K, et al. High prevalence of human cytomegalovirus in prostatic intraepithelial neoplasia and prostatic carcinoma. J Urol 2003;170:998-1002.

37 Huang ES, Roche JK. Cytomegalovirus D.N.A. and adenocarcinoma of the colon: evidence for latent viral infection. Lancet 1978;i:957-960.

38 Hashiro GM, Horikami S, Loh PC. Cytomegalovirus isolations from cell cultures of human adenocarcinomas of the colon. Intervirology 1979;12:84-88.

39 Harkins L, Volk AL, Samanta M, et al. Specific localisation of human cytomegalovirus nucleic acids and proteins in human colorectal cancer. Lancet 2002;360:1557-1563.

40 Brichacek B, Hirsch I, Zavadova H, et al. Absence of cytomegalovirus DNA from adenocarcinoma of the colon. Intervirology 1980;14:223-227.

41 Hart H, Neill WA, Norval M. Lack of association of cytomegalovirus with adenocarcinoma of the colon. Gut 1982;23:21-30.

42 Boguszakova L, Hirsch I, Brichacek B, et al. Absence of cytomegalovirus, Epstein-Barr virus, and papillomavirus DNA from adenoma and adenocarcinoma of the colon. Acta Virol 1988;32:303-308.

43 Stevenson K, Macnab JCM. Cervical carcinoma and human cytomegalovirus. Biomed Pharmacother 1989;43:173-176.

44 Thompson CH, Rose BR, Elliott PM. Cytomegalovirus and cervical cancer: failure to detect a direct associa- tion or an interaction with human papillomaviruses. Gynecol Oncol 1994;54:40-46.

45 Chan PK, Chan MY, Li WW, et al. Association of human beta-herpesviruses with the development of cervical cancer: bystanders or cofactors. J Clin Pathol 2001;54:48-53.

46 Poland SD, Costello P, Dekaban GA, et al. Cytomegalovirus in the brain: in vitro infection of human brain-derived cells. J Infect Dis 1990;162: 1252-1262.

47 Wrensch M, Weinberg A, Wiencke J, et al. Prevalence of antibodies to four herpesviruses among adults with glioma and controls. Am J Epidemiol 2001;154: 161-165.

48 Niedobitek G, Finn T, Herbst H, et al. Detection of cytomegalovirus by in situ hybridisation and immunohistochemistry using new monoclonal antibody CCH2: a comparison of methods. J Clin Pathol 1988; 41:1005-1009.

49 Wirgart BZ, Landqvist M, Hokeberg I, et al. Early detection of cytomegalovirus in cell culture by a new monoclonal antibody, CCH2. J Virol Methods 1990;27: 211-220.

50 Saiz E, Lubin J, Robinson MJ. The modified Steiner stain: a new use for an old stain? Staining cytomegalovirus infected cells in gastrointestinal biopsies. Histochem J 1998;30:549-552.

51 Lantos PL, Louis DN, Rosenblum MK, et al. Tumours of the nervous system. In: Harris DI, Lantos PL (eds). Greenfield's Neuropathology, 7th edn. Arnold: London, 2002, pp 767-779. 